\title{
A Comparative Eifectiveness Study of Bone Density Changes in Women Over 40 Following Three Bone Health Plans Containing Variations of the Same Novel Plant-sourced Calcium
}

\author{
Gilbert R. Kaats ${ }^{1 凶}$, Harry G. Preuss ${ }^{2}$, Harry A. Croft ${ }^{3}$, Samuel C. Keith ${ }^{1}$, and Patti L. Keith ${ }^{1}$ \\ 1. Integrative Health Technologies, Inc., 4940 Broadway, San Antonio, Texas 78209, USA; \\ 2. Professor of Biochemistry, Physiology, Medicine, \& Pathology, Georgetown University Medical Center, Washington D.C. \\ 20057, USA; \\ 3. Croft Research Group, San Antonio, TX, USA.
}

$\triangle$ Corresponding author: Gilbert R. Kaats, Integrative Health Technologies, Inc., 4940 Broadway, San Antonio, Texas, 78209. Tel: (210)824-4200. Fax: (210) 824-4715 Email: grk@ihtglobal.com.

\footnotetext{
(C) Ivyspring International Publisher. This is an open-access article distributed under the terms of the Creative Commons License (http://creativecommons.org/ licenses/by-nc-nd/3.0/). Reproduction is permitted for personal, noncommercial use, provided that the article is in whole, unmodified, and properly cited.
}

Received: 2011.02.02; Accepted: 2011.02.25; Published: 2011.03.02

\begin{abstract}
Background: The US Surgeon General's Report on Bone Health suggests America's bone-health is in jeopardy and issued a "call to action" to develop bone-health plans incorporating components of (I) improved nutrition, (2) increased health literacy, and (3) increased physical activity.

Objective: To conduct a Comparative Effectiveness Research (CER) study comparing changes in bone mineral density in healthy women over-40 with above-average compliance when following one of three bone health Plans incorporating the SG's three components.

Methods: Using an open-label sequential design, 414 females over 40 years of age were tested, 176 of whom agreed to participate and follow one of three different bone-health programs. One Plan contained a bone-health supplement with I,000 IUs of vitamin $D_{3}$ and 750 $\mathrm{mg}$ of a plant-sourced form of calcium for one year. The other two Plans contained the same plant form of calcium, but with differing amounts of vitamin $D_{3}$ and other added bone health ingredients along with components designed to increase physical activity and health literacy. Each group completed the same baseline and ending DXA bone density scans, 43-chemistry blood test panels, and 84-item Quality of Life Inventory (QOL). Changes for all subjects were annualized as percent change in BMD from baseline. Using self-reports of adherence, subjects were rank-ordered and dichotomized as "compliant" or "partially compliant" based on the median rating. Comparisons were also made between the treatment groups and two theoretical age-adjusted expected groups: a non-intervention group and a group derived from a review of previously published studies on non-plant sources of calcium.

Results: There were no significant differences in baseline BMD between those who volunteered versus those who did not and between those who completed per protocol (PP) and those who were lost to attrition. Among subjects completing per protocol, there were no significant differences between the three groups on baseline measurements of BMD, weight, age, body fat and fat-free mass suggesting that the treatment groups were statistically similar at baseline. In all three treatment groups subjects with above average compliance had significantly greater increases in BMD as compared to the two expected-change reference groups. The group following the most nutritionally comprehensive Plan outperformed the other two groups. For all three groups, there were no statistically significant differences between baseline and ending blood chemistry tests or the QOL self-reports.
\end{abstract}




\begin{abstract}
Conclusions: The increases in BMD found in all three treatment groups in this CER stand in marked contrast to previous studies reporting that interventions with calcium and vitamin $D_{3}$ reduce age-related losses of BMD, but do not increase BMD. Increased compliance resulted in increased BMD levels. No adverse effects were found in the blood chemistry tests, self-reported quality of life and daily tracking reports. The Plans tested suggest a significant improvement over the traditional calcium and vitamin $D_{3}$ standard of care.
\end{abstract}

Key words: bone mineral density, bone-health supplement, women over-40

\section{Introduction}

In the 2010 update to its 2004-2009 Strategic Plan [1], NIH's Office of Dietary Supplements (ODS) encourages research assessing the effects of dietary supplements on biomarkers associated with chronic diseases, optimal health and improved performance. One major biomarker of ODS's goal was addressed in the Surgeon General's Report on Bone Health [2] estimating that by 2020 half of all American citizens over 50 will be at risk of fractures due to poor bone health. The SG concluded that there is a bone health crisis in America due to increasingly sedentary lifestyles, absence of current information about bone health, and inadequate nutrition. The SG recommended that people of all ages take steps to improve their bone density (BMD) by ensuring that they are getting the recommended amounts of calcium and vitamin $\mathrm{D}_{3}$, and that supplementation may be helpful in meeting these nutritional goals. Based on findings in the Surgeon General's Report on Bone Health, a "call to action" was issued for the development of bone health plans that incorporate three components: (1) increased physical activity (2) improved health literacy, and (3) improved nutrition.

In spite of the SG's "call to action", calcium deficiencies remain prevalent throughout the world [3] as well as in the US [4]. In addition to the persistence of sedentary lifestyles, poor nutritional habits, and lack of health literacy, there are other challenges to America's bone health that could benefit from supplementation. The increasing number of the elderly is extending the progressive age-related decline in BMD, thereby increasing the need for additional supplemental calcium and vitamin $\mathrm{D}_{3}$ [5]. There are concerns that current farming techniques are depleting the nutritional composition of vitamins and minerals in our food supply [6-8]. A wide number of diseases and medications have been found to have concomitant adverse effects on bone health [9-13] including the increasing use of SSRIs for the treatment of depression [14-17] and contraceptives [18]. Since intentional and unintentional weight loss typically depletes bone density [19-30] Americans obsession with dieting will increase the need for supplementation. This is also true for the ten-fold increase in the number of bariatric surgeries performed in the U.S. to combat the adverse effects on bone health found associated with these surgeries [31,32]. In addition to the decline in bone health associated with sedentary lifestyles, excessive physical activity observed in athletes, particularly young athletes, has been shown to have adverse effects on bone health, which could be improved with supplementation [33-34]. These factors suggest that the SG's 2004 call to action to develop safe and effective bone health plans is as relevant today as it was six years ago, and there is an extensive body of evidence suggesting supplementation with calcium and vitamin $\mathrm{D}_{3}$ could help reverse what the SG concludes is a crisis in bone health.

Much of the evidence supporting the value of calcium supplementation is summarized in an exhaustive meta-analysis [5] of randomized trials involving 63,897 subjects 50 years of age and older, most of whom were healthy postmenopausal women with an average age of 67.8 years. The meta-analysis includes 23 trials of 41,419 subjects in which changes in BMD were the outcome measure, or one of the outcome measures. No studies reported that supplementation worsened age-related declines in BMD. Nor were there any studies suggesting that supplementation increased BMD over the study period. The overall finding was that with or without vitamin $\mathrm{D}_{3}$, calcium supplementation was associated with a "reduced rate of bone loss".

In view of these findings, studying another "me too" or "more of the same" product that also simply slows BMD loss would not help to solve the bone health crisis. What seemed more promising was a bone health plan with potential to halt, or even reverse, age-related BMD loss- a goal made possible with the Comparative Effective Research (CER) model. As The American College of Physicians defines it, CER studies evaluate the relative clinical effectiveness, safety, and cost of two or more medical services, drugs, devices, therapies, or procedures used to treat the same condition [35]. Without demonstrating the superiority over the existing standard of care and 
competing interventions, the acceptability of an intervention becomes heavily dependent upon a company's marketing capability, as opposed to product superiority proven with safety and efficacy test results [36]. The emphasis of CER studies is to demonstrate the superiority of existing products and standards of care [37]. These types of studies span available interventions from pharmaceutical treatment, to lifestyle modifications such as diet, physical activity, and complementary and alternative therapies that are often initiated without physician input. But CER studies face publication challenges that need a paradigm shift in the scientific community to gain acceptance when competing against studies using placebo or control group protocols [38-41].

The purpose of this research was to conduct a CER study comparing changes in baseline BMD in healthy women over 40 years of age who followed one of the three different bone health Plans shown in Table 1.

Comparisons were also made with two references groups of the same age and gender that were used to calculate expected changes, one without any form of intervention, and the other using changes reported in studies using a variety of non-plant sources of calcium.

Table I. Components/ingredients in the three bone-health plans

\begin{tabular}{llll}
\hline Ingredient or Component & Plan 1 & Plan 2 & Plan 3 \\
\hline Plant-sourced Calcium (mg) & 750 & 720 & 756 \\
Trace Minerals in AlgaeCal (mg) & 1,771 & 1,608 & 1,692 \\
Magnesium (mg) & 65 & 72 & 350 \\
Vitamin D-3 (IUs of Cholecalciferol) & 1,000 & 800 & 1,600 \\
Vitamin K-2 as MK-4 (mg) & 0 & 1.5 & 0 \\
Vitamin K-7 as MK-7 (mcg) & 0 & 0 & 100 \\
Boron (mg) & 0 & 0 & 3 \\
Vitamin C (mg) & 0 & 0 & 50 \\
Strontium Citrate (mg) & 0 & 680 & 680 \\
Pedometer-based activity program & No & Yes & Yes \\
Health Literacy Information & No & Yes & Yes \\
\hline
\end{tabular}

*72 mg naturally occurring plus magnesium carbonate

\section{Materials and Methods}

The protocol for Plans 2 and 3 were approved by the RCRC Institutional Review Board (www.RCRCIRB.com), Austin, TX, Protocol number 1252006. The protocol for Plan 1 was approved by the researcher's ethics committee. Considerable effort was expended to recruit and enroll subjects using the same enrollment procedures in order to facilitate between-group comparisons on relevant outcome measures.

Due to budget restrictions, instead of simultaneously enrolling a control group, the study sponsor chose to compare the three treatment groups effects with a pre-existing annualized expected change in BMD for women over 40 years of age, derived from data showing that after midlife there is an age-related yearly loss in both sexes of 1\% [42] and an accelerated loss of up to $2 \%$ for 14 years for women of menopausal age [43]. Additional data were obtained from norms provided by the DXA equipment manufacturer (GE Lunar), the researcher's database of over 26,000 total body measurements, and from the National Os- teoporosis Foundation [44]. Based on these sources, we estimated a non-treatment effect of $0.75 \%$ per year. This may be a somewhat conservative estimate in view of population-based longitudinal studies suggesting that, starting at age 40 , there is minor, but significant, annual bone loss [45] that increases to $0.5 \%$ to $0.9 \%$ a year in perimenopausal women [46-49], to above $1 \%$ after menopause $[48,49]$ after which the decline remains about $1 \%[45,50,51]$. Other studies suggest after midlife there is an age-related yearly loss of bone in both sexes of $1 \%$ [52] which is accelerated to $2 \%$ for up to 14 years in women around the age of menopause [53]. In men, a small loss is detected in 40 -year olds [45] that increases to a $\sim 0.8 \%$ per year into old age [45,50-52]. More recently, another review has suggested that women will lose $35 \%$ to $39 \%$, men $17 \%-19 \%$, of lifetime bone loss after achieving peak bone mass at ages 30-40 years [54], changes that are consistent with the previously cited studies.

Another comparison was also made between the 3 active treatment groups with a $-0.1 \%$ expected annualized changes in BMD when taking vitamin $\mathrm{D}_{3}$ and non-plant sources of calcium. This calculation 
was made from studies cited in Tang et al.'s [5] exhaustive review and additional data provided in studies [55-59] not cited in Tang et al.'s review. The general conclusion from these studies is that supplementation with calcium and vitamin $\mathrm{D}$ can slow age-related declines in BMD, but none of these studies suggested that supplementation can increase BMD levels.

Improved nutrition. The bone-health supplements in these plans were analyzed by Exova Labs, Chicago, IL for confirmation of nutrient levels and absence of heavy minerals and other contaminating ingredients. Calcium, magnesium and other minerals were validated by Advanced Labs, Salt Lake City, UT.

The supplement provided to all study groups contained a plant-sourced form of calcium with a research identity of DN0361 (commercially known as 'AlgaeCal' or 'AC') made by milling whole, live-harvested sea algae found on the South American coastline. In addition to calcium, the algae contained other naturally occurring minerals in the following rank-order of percentage: carbon, chloride, magnesium, manganese, selenium, silicon, sodium, strontium, titanium and vanadium, boron, silica, and copper. Many of these minerals have been reported to play a role in bone health. A recent in-vitro study [60] demonstrated superiority over the two most commonly used calcium salts: calcium carbonate and calcium citrate. Cultured human osteoblast cells (hFOB 1.19) were treated with $\mathrm{AC}$, calcium carbonate or calcium citrate. Alkaline phosphatase activity was significantly increased with AC treatment when compared to control, calcium carbonate or calcium citrate (4.0, 2.0 and 2.5-fold, respectively). Proliferating cell nuclear antigen expression (immunocytochemical analysis), DNA synthesis (4.0, 3.0 and 4.0 fold, respectively) and Ca2+ deposition (2.0, 1.0 and 4.0 fold, respectively) were significantly increased in $A C$ treated cells when compared with control, calcium carbonate, or calcium citrate treatment. AC treatment significantly reduced oxidative stress when compared to calcium carbonate or calcium citrate $(1.5,1.4$ fold, respectively). This earlier study demonstrated that AC exhibited unique properties compared to calcium carbonate or calcium citrate on a cellular level, which suggests the need for human intervention studies such as the present study. Furthermore, safety and toxicological investigations were conducted using AC and demonstrated its broad spectrum safety [61].

Health literacy. To provide a health literacy component, with permission from the author, subjects following Plans 1 and 2 were provided with reprints from Chapters 5, 8, $9 \& 10$ of a published book dealing with changes in body composition [62]. These chap- ters provided information on bone density and on the pedometer-based physical activity program. Calorie estimation charts and glycemic load tables of over 300 common foods designed to increase the quality of carbohydrate intakes were also included [62]. Additional health awareness was gained from the consistent stream of feedback from the pedometer-based program described below.

Physical Activity. To increase physical activity levels, subjects were asked to wear a pedometer during their waking hours and to record and track their daily activity levels using the charts and graphs provided in their health literacy booklet. They were also asked to follow the instructions for personalizing the pedometer program to their personal goal weight. The Digi-Walker pedometer (HealthTech Products, LLC, San Antonio, TX) used in this study is considered among the most reliable and valid of pedometers available $[63,64]$.

Subjects. For all three plans, subjects were contacted using the investigators' DXA (Total Body Dual-energy X-ray Absorptiometry) database, from participants at a local health fair, and from referrals from subjects who agreed to participate. All subjects certified that they had reviewed the Informed Consent with their personal healthcare provider or physician and that they had no medical conditions that would preclude their participation. However, pregnant and lactating women were excluded irrespective of this certification. Subjects were asked to refrain from taking other bone-health supplements during the study. In all three treatment groups, subjects and research technicians were blinded with regard to the subjects' baseline test results. For Plan 1, 60 adults completed a baseline DXA test, 58 agreed to participate for the one-year study period and 35 ultimately completed the study per-protocol (PP). For Plan 2, a total of 274 $S^{\prime}$ s were invited to complete a bone density test and to have the study components explained to them prior to enrolling for the study. Of these, 158 agreed to participate, 125 of whom ultimately completed the study PP. For Plan 3, 80 adults were invited to complete a bone density test and to have study components explained to them prior to enrolling, 58 of whom agreed to participate and 51 completed the study PP. Figure 1 shows a flow diagram through the study for the three study groups.

To encourage candid reporting to allow for dose-related and compliance comparisons, all enrolled subjects were paid a "reporting fee" of $\$ 2.00 /$ day for providing daily reports of their supplement usage and side effects. Throughout the study, subjects were repeatedly reminded that this fee was not an incentive for taking the product, but rather was 
for the purpose of encouraging candid reporting to allow for analyses of the effects of adherence. Subjects were also advised that the reporting fees would be paid irrespective of product usage as long as the participant completed all ending tests. This procedure was also designed to provide an additional measure of product efficacy on the assumption that if a plan was efficacious, compliant subjects should outperform partially compliant subjects.
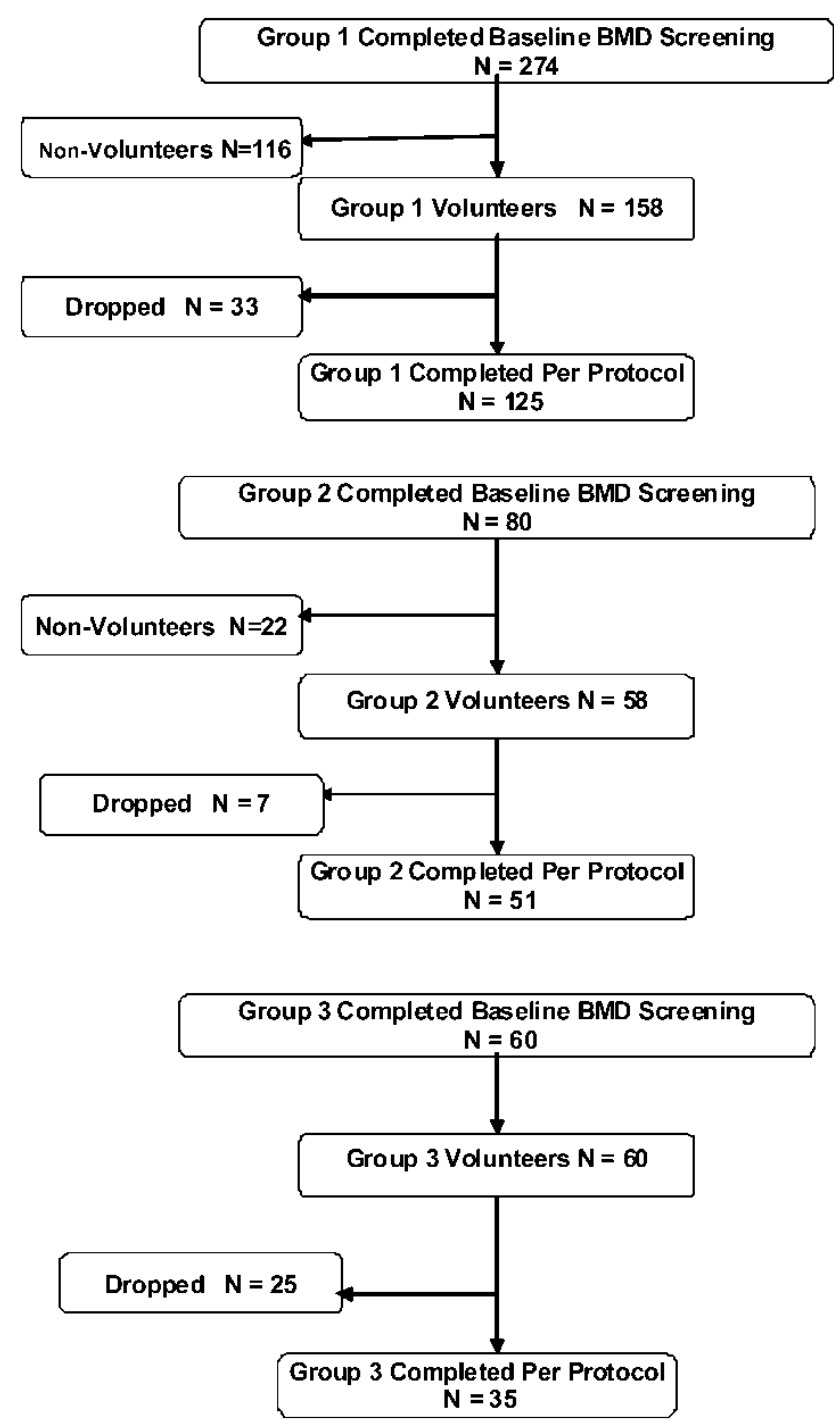

Figure I. Flow of participants through the three study legs
Outcome Measure of efficacy. Although the primary outcome measure for all three study groups was changes in BMD among highly compliant subjects when following each of the three plans, data was also reported for the entire cohort for each Plan. BMD was assessed by dual-energy X-ray absorptiometry (DXA) total body scans (GE Lunar, LUNAR Corporation, Madison, WI, USA). Longitudinal precision of the DXA unit was monitored using repeated measures of total bone density phantoms provided by the manufacturer.

Outcome Measure of safety. To assess safety in all three Plans at baseline and at the end of the study period, subjects completed the 50-item Quality of Life inventory [64] shown in Table 2, the 43-item blood chemistry panel shown in Table 3, and daily tracking self-reports on positive/negative reactions to the product and product usage.

Compliance. In order to obtain a compliance rating (since poor compliance is a major obstacle to obtaining the full benefit of bone-health supplements) [5], the research technician who had the most frequent contact with S's (subjects) rated the subjects' compliance with the protocol using a 5-point scale. Each group was then rank-ordered and dichotomized at the median. When making these ratings and classifications, both the technician and the investigator were blinded with respect to the subject's BMD measurements. Those above the median were classified as "compliant", and those below the median were classified as "partially compliant."

\section{Statistical Methods}

Since the study period for Plan 1 was one year and the study period was six-months for Plans 2 and 3 , BMD changes and comparisons were reported as mean annualized percent change (MPAC). Annualizing changes also allowed easier comparisons with other studies reported in the literature.. Continuously distributed data were summarized with the mean and standard deviation; binary outcomes were summarized with counts and percents. Study groups were contrasted on MAPC (Mean Annualized Percent Change in BMD) with analyses of covariance with adjustment for age and sex. Group contrasts with regard to binary outcomes were made with Pearson's chi-square. All statistical testing was 2-sided with a significance level of 5\%. SAS Version 9.1.3 for Windows (SAS Institute, Cary, North Carolina) was used throughout. 
Table 2. Quality of Life Inventory

\begin{tabular}{|c|c|}
\hline \multicolumn{2}{|c|}{$\begin{array}{l}\text { Report problems occurring over the last } 30 \text { days rating: } \\
0=\text { None, } 1=\text { Minor, } 2=\text { Major and } 3=\text { Severe }\end{array}$} \\
\hline 1 Headaches & 26 Irregular heartbeat \\
\hline 2 Irritable bowel syndrome & 27 Shortness of breath \\
\hline 3 Arthritis & 28 Constipation \\
\hline 4 Premenstrual syndrome & 29 Stomach gas or indigestion \\
\hline 5 Recurring sinus infections & 30 Feeling weak \\
\hline 6 Tension fatigue syndrome & 31 Eating too rapidly \\
\hline 7 Recurrent anxiety & 32 Eating after being full \\
\hline 8 Recurrent depression & 33 Embarrassed about overeating \\
\hline 9 Insomnia & 34 Depressed over eating habits \\
\hline 10 Low self esteem & 35 Depressed about my weight \\
\hline 11 Binge eating & 36 Difficult to stop eating \\
\hline 12 Chronic tension & 37 Worrying about the future \\
\hline 13 Lack of energy & 38 Unable to concentrate \\
\hline 14 Food allergies & 39 Forgetfulness \\
\hline 15 Feeling under stress & $40 \mathrm{Bad}$ temper or quick to anger \\
\hline 16 Cancer & 41 Indigestion \\
\hline 17 Prostate problems & 42 Diabetes \\
\hline 18 Overeating & 43 Vomiting \\
\hline 19 Stomach pain & 44 Heartburn \\
\hline 20 Back pain & 45 Esophageal reflux \\
\hline 21 Pain in arms, legs, or joints & 46 Control over my appetite \\
\hline 22 Menstrual pain or problems & 47 Ability to relax \\
\hline 23 Chest pain & 48 Heart disease \\
\hline 24 Dizziness & 49 Fibromyalgia \\
\hline 25 Diarrhea & 50 Difficulty in falling asleep \\
\hline
\end{tabular}

Table 3. Listing of Blood Chemistries

\begin{tabular}{ll}
\multicolumn{1}{c}{ LIPID PANEL } & \multicolumn{1}{c}{ CBC (INCLUDES DIFF/PLT) } \\
TRIGLYCERIDES & WHITE BLOOD CELL COUNT \\
CHOLESTEROL, TOTAL & RED BLOOD CELL COUNT \\
HDL CHOLESTEROL & HEMOBLOBIN \\
LDL CHOLESTEROL & HEMATOCRIT \\
CHOL/HDLC RATIO & MCV \\
\multicolumn{1}{c}{ METABOLIC PANEL } & MCH \\
GLUCOSE & MCHC \\
UREA NITROGEN (BUN) & RDW \\
CREATININE & PLATELET COUNT \\
BUN/CREATININE RATIO & ABSOLUTE NEUTROPHILS \\
SODIUM & ABSOLUTE LYMPHOCYTES \\
POTASSIUM & ABSOLUTE MONOCYTES \\
CHLORIDE & ABSOLUTE EOSINOPHILS \\
CARBO DIOXIDE & ABSOLUTE BASOPHILS \\
CALCIUM & NEUTROPHILS \\
PROTEIN, TOTAL & LYMPHOCYTES \\
ALBUMIN & MONOCYTES \\
GLOBULIN & EOSINOPHILS \\
ALBUMIN/GLOBULIN RATIO & BASOPHILS \\
BILIRUBIN, TOTAL & \multicolumn{1}{|c}{ OTHER MEASURES } \\
ALKALINE PHOSPHATASE & C-REACTIVE PROTEIN CARDIO CRP) \\
AST & TSH W/REFLEX TO FT4 \\
ALT & \multicolumn{1}{|c}{} \\
\hline
\end{tabular}




\section{Results}

All subjects. As shown in the baseline characteristics in Table 4, with the exception of the higher level of body fat in subjects following Plan 1 vs. Plan 2 , there were no significant differences between the three groups in baseline BMD or in the 4 variables related to $\mathrm{BMD}$, thus suggesting that the treatment groups were statistically similar in spite of the sequential enrollment of subjects. There also were no differences on these baseline demographics between subjects who chose not to enroll and those who completed PP, or between those who enrolled, but dropped out, as compared to those who completed PP. Subjects in all three plans had an increase in MAPC: Plan 1=1.20\%, Plan 2=0.33\%, and Plan 3=2.5\%. Using a repeated measures t-test, MAPC in Plan 1 and 3 were significant $(\mathrm{P}=0.027$ and $\mathrm{P}=0.002$ respectively), but the MAPC in Plan 2 failed to reach significance $(\mathrm{P}=0.430)$. However, the MAPC in all three Plans was significant when compared to the expected-change non-intervention normative group $(\mathrm{P}<0.001)$ and the reference group derived from a literature review $(\mathrm{P}<0.001, \mathrm{P}=0.026$, and $\mathrm{P}<0.001$ respectively.

Compliant sub-groups. As shown in the baseline characteristics in Table 5, with the exception of the higher BMD in Plan 3 as compared to Plan 1 $(\mathrm{P}=0.025)$, and the higher scale weight in Plan 2 versus Plan 3, there were no significant differences between the baseline demographics for the three groups, suggesting that they were reasonably similar at baseline. Among the compliant sub-group, there also was no significant differences on these baseline demographics between subjects who chose not to enroll and those who completed PP, or between those who enrolled, but dropped, as compared to those who completed PP.

Table 4. Means and between-group t-tests of baseline demographic measures for subjects following one of the three bone-health plans.

\begin{tabular}{lccccc}
\multicolumn{1}{r}{ Study Plans } & Age & Wgt & BMD & Fat & FFM \\
Plan-1 N=36 & 56.1 & 162.5 & 1.132 & 70.4 & 92.2 \\
Plan-2 N=102 & 57.1 & 154.3 & 1.123 & 65.7 & 92.2 \\
Plan-3 N=34 & 59.0 & 162.7 & 1.095 & 65.9 & 96.8 \\
Plan-1 vs. Plan-2 & 0.583 & 0.230 & 0.650 & 0.105 & 0.304 \\
Plan-1 vs. Plan-3 & 0.218 & 0.985 & 0.144 & 0.014 & 0.555 \\
Plan-2 vs. Plan-3 & 0.344 & 0.379 & 0.190 & 0.171 & 0.965 \\
\hline
\end{tabular}

Table 5. Means and between-group t-tests of baseline demographic measures for compliant sub-groups in each of the three Plans.

\begin{tabular}{lccccc}
$\quad$ Treatment Plan & Age & Wgt & BMD & Fat & FFM \\
Plan 1 N=36 & 69.5 & 150.0 & 1.113 & 62.1 & 87.9 \\
Plan 2 N=51 & 58.8 & 158.2 & 1.125 & 69.0 & 95.1 \\
Plan 3 N=17 & 50.4 & 143.4 & 1.146 & 58.5 & 89.3 \\
Plan 1 vs. Plan 2 & 0.147 & 0.086 & 0.102 & 0.198 & 0.071 \\
Plan 1 vs. Plan 3 & 0.052 & 0.369 & 0.025 & 0.637 & 0.116 \\
Plan 2 vs. Plan 3 & 0.674 & 0.035 & 0.677 & 0.116 & 0.529 \\
\hline
\end{tabular}

As shown in Figure 2, subjects following all three plans had an increase in MAPC: Plan $1=1.30 \%$, Plan $2=2.00 \%$, and Plan $3=4.1 \%$. Using a repeated-measures t-test, the MAPC from baseline in all three Plans was significant $(P=0.003, P=<0.001$, and $P=0.003$, respectively). The MAPC in Plan 3 was significantly greater than Plan $1(P=0.002)$, but was not significantly greater than Plan $2(P=0.262)$ nor was the difference between Plan 1 and Plan $2(P=0.063)$. Although not shown in Figure 2 since we had no com- pliance data on the two expected change groups, comparisons between the three Plans and all subjects in both expected change groups revealed that the MAPC in all three Plans was significantly greater $(P<0.001)$ than both of these groups.

With regard to the QOL shown previously in Table 2, there were no significant baseline/ending changes in any of the 50 items or in a total QOL score (the sum of all 50 items). Assessment of safety using the QOL is straight-forward. An increase in the total 
scale or individual item scores suggests increased risk and potential adverse effects. Similarly, evaluation of changes in cholesterol, LDL, Triglycerides, HDL/Total ratio, glucose, and C-reactive protein; and decreases in HDL suggest a negative outcome and potential adverse reaction. In all three Plans, there were no statistically significant changes in any of these "uni-directional" test scores. However, evaluating changes in the remaining 37 chemistries is less straight forward since they are "multi-directional" where both increases or decreases could be associated with either positive or negative outcomes. Addition- ally, with the remaining 37 chemistries, it is probable that some changes could be statistical artifacts. Therefore, instead of using changes from baseline in all 37 chemistries, we compared the number of changes in scores that were in the normal or acceptable ranges at baseline with those that became abnormal or unacceptable by the end of the study. In all three groups and sub-groups, none of the normal scores were abnormal by the end of the study. Thus, it was our conclusion that the absence of changes in the unit- and multi-directional blood chemistries supports the safety of the Plans.

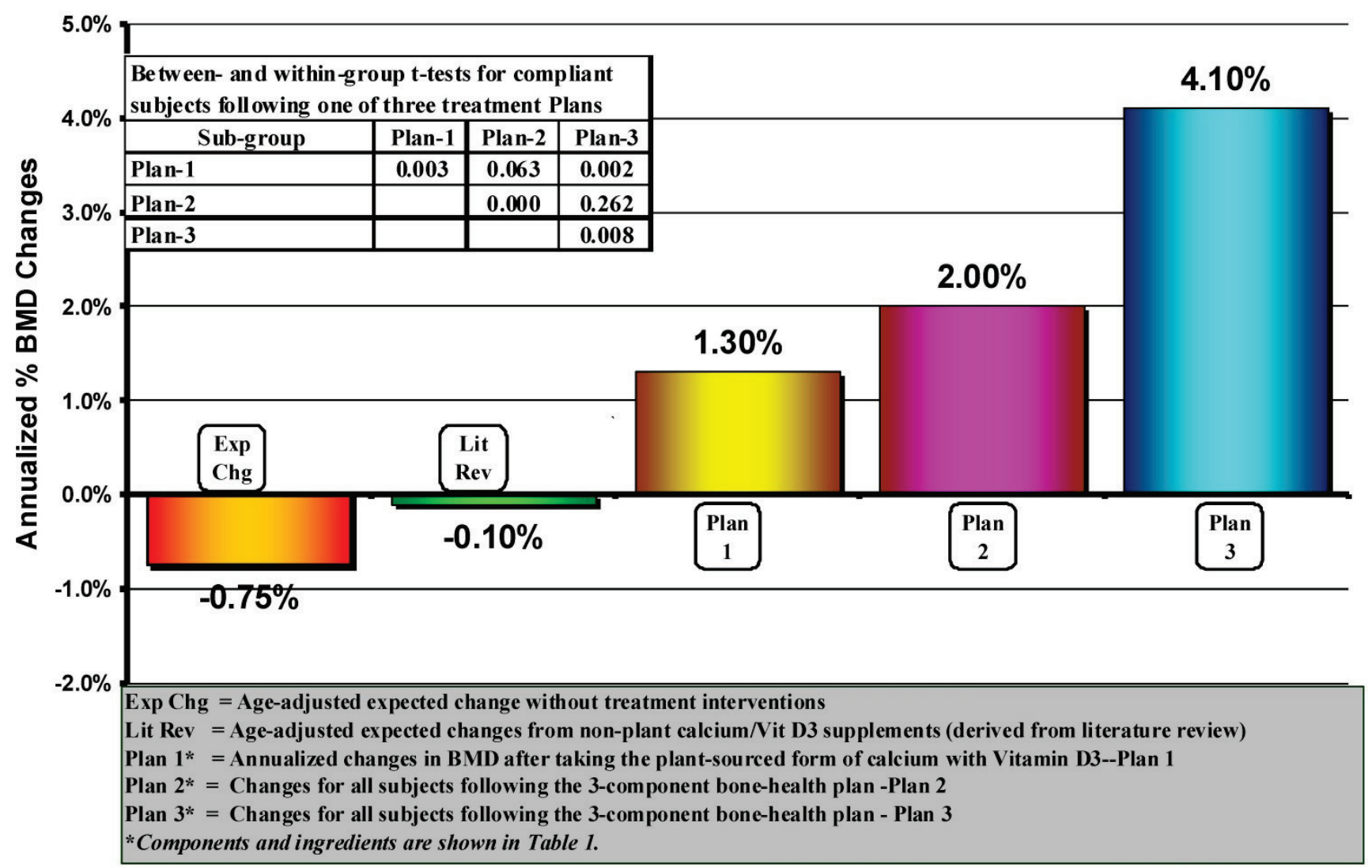

Figure 2. Within- and between-groups comparisons of annualized changes in Bone Mineral Density (BMD) in women over 40 who followed one of three different bone-health treatment plans and who were rated in the upper $50 \%$-ile of protocol compliance. $\mathrm{P}$ levels on the diagonal represent changes from baseline using within-group repeated measures $\mathrm{t}$-tests.

\section{Discussion}

This CER study was designed to compare the safety and efficacy of three bone health Plans using three independent sequentially enrolled groups of healthy women 40 years of age and older. The primary outcome measure was changes in baseline BMD (Bone Mineral Density) among participants with above average compliance in order to examine the safety and efficacy in people complying with the bone health plans as designed. However, additional analyses were also conducted using all subjects in each of the three study cohorts. Within-group comparisons of changes in BMD from baseline and between-group comparisons with the two different expected change reference groups support the safety and efficacy of all 
three Plans. It is also noteworthy that all three bone health plans facilitated outright increases in BMD, a finding that stands in marked contrast to a plethora of studies suggesting that calcium and vitamin $\mathrm{D}_{3}$ supplementation can, at best, only slow down the age-related decline in BMD.

Notwithstanding the evidence presented in this study, one could conclude that the increased MAPC from baseline and over-expected was attributable to using a sequential design with subject groups with unequal baseline demographic characteristics. The absence of a placebo-controlled arm raises concerns about placebo effects. Questions may also be raised about the validity of the two expected change reference groups to which changes in BMD in the three Plans were compared. Furthermore, the reported increase, instead of slowing, of BMD attributable to the three bone health plans stands in marked contrast to previous research and warrants further comment.

With regard to the equivalence of the groups, while it is impossible to rule out all potentially confounding variables, increased confidence in the similarity of the three groups was obtained from a comparison of baseline demographic measures of the groups that found, in general, no statistical differences between the groups in BMDs or in variables affecting BMD (weight, gender, lean mass, \% fat, and BMI), in any of the 43 baseline blood chemistries, or in the QOL analyses. In all three groups, there were no differences in baseline demographics between volunteers and non-volunteers, or between those subjects who completed versus those who dropped out. Taken together, these similarities provide considerable evidence that the three groups were reasonably equivalent.

With regard to placebo effects, it seems implausible to suggest that the reported positive changes in BMD were the result of placebo effects, when the placebo groups in almost all pharmaceutical and nutritional interventions lost BMD. For example, three randomized double-blinded placebo-controlled studies measuring the effects of strontium ranelate [65-67] found a progressive and linear decrease in BMD in placebo groups for each of the three study years--a $1 \%$ annual decline which was virtually identical to the age-gender adjusted expected changes used in this study. In contrast to the absence of studies on placebo effects on BMD, a number of studies have suggested that consumption of the multiple nutrients in the $\mathrm{AC}$ formulas could facilitate increases in BMD [68]. Considerable evidence is available on the bone-health effects of the nutrients in the AlgaeCal formula--supplemental magnesium, vitamin K-2, calcium and Vitamin $\mathrm{D}_{3}$ [69-70]. Vitamin $\mathrm{C}$ has also been re- ported as an essential nutrient for collagen formation and normal bone development, particularly in older men and women [71-72].

With regard to the validity of the two expected change reference groups, in the non-intervention group, the estimate for an annual $-0.75 \%$ decline in BMD appears conservative. The women in this study had an average age of 57.4 (41-89) which is consistent with the age-related decline of $1 \%$ to $2 \%$ cited above for women of menopausal age as well as with the data reported in the meta-analysis. As for the estimate for expected changes in BMD from traditional calcium supplementation found in the literature review, the annual decline of $0.10 \%$ is also conservative based on the studies we reviewed as well as the studies reviewed in the meta-analysis cited above.

As for the unusual finding of the increased BMD levels found in the three study groups, the superiority of Plan 3 over Plan 1 suggests that the physical activity and health literacy components may have made contributions beyond the effects of supplementation alone. As for BMD increases in Plan 1, without these components, and without definitive data, some of the explanation may be attributed to what appears to be optimal levels of vitamin $\mathrm{D}_{3}(1,000 \mathrm{IU})$ and calcium $(750 \mathrm{mg})$ that were in the Plan 1 version of AC. An additional benefit may be attributed to the use of a plant-sourced form of calcium that, as discussed above, appears to be more bio-available than more traditional forms of calcium. Additionally, there are studies [68,73-78] supporting the suggestion that plant-sourced minerals may be more easily absorbed than non-plant-sourced calcium and minerals, and that the body is able to use less than 10 percent of the minerals contained in the most popular brands of multivitamins, as opposed to over 80 percent of minerals derived from plant sources. Other studies have also reported positive associations between fruit and vegetable consumption and BMD in elderly adults [77-79], adolescents [80] and children [81]. Another potential explanation is that, although total body BMD is highly correlated with spinal and femur measurements, the total body measurement is less affected by the more subjective judgments made with spine and femur. In contrast to total body measurements where the operator needs only to position the patient on the scanning table, but does not need to make the more subjective decisions regarding the spinal lumbar and femoral regions.

\section{Conclusions}

This study found that following any of the three Plans was associated with increases in BMD as opposed to merely slowing down the decline in BMD, 
which had been the general conclusions from a wide range of studies on the efficacy of vitamin D and calcium supplementation. These increases occurred without adverse side effects. While the study also provides evidence of the benefit of adding the physical activity and health literacy components, the data also support the efficacy of plant-source calcium as a stand-alone product.

\section{Authors' Contributions}

Kaats GR was the principal investigator; he secured and audited all study data, conducted all of the statistical analyses, and contributed significantly to the preparation and submission of the manuscript. Preuss HG contributed to the study design, data interpretation and manuscript review and preparation. Croft HA provided medical supervision. Keith SC conducted DXA testing, aided in study design, preparation of the Informed Consent and computerizing of all study data. Keith PL also aided in study design, preparation of the Informed Consent, aided in enrollment of subjects, had weekly contact with all subjects, conducted DXA testing, provided subjects with requisitions to conduct off-site blood testing, and reviewed and explained the informed consent form and edited, revised, and proofed the manuscript.

\section{Abbreviations}

AC: AlgaeCal; BMD: Total Body Bone Mineral Density; SG: United States Surgeon General; CER: Comparative Effective Research; DXA: Total Body Dual-energy X-ray Absorptiometry; MAPC: Mean Annualized Percent Change in BMD; S's: subjects; Plan (or The Plan): the plan under study, incorporating components to promote health, literacy, increased physical activity, and improved nutrition; PP: per protocol; QOL: a 50-item Quality of Life questionnaire.

\section{Competing Interests}

Dr. Kaats holds equity in Integrative Health Technologies, Inc., a public company which holds a minority of shares in the grantor company. All other authors declare that they had no competing interests.

\section{Conflict of Interest}

The authors have declared that no conflict of interest exists.

\section{References}

1. [Internet] The Office of Dietary Supplements - National Institutes of Health. Promoting Quality Science in Dietary Supplement Research, Education, and Communication: A Strategic
Plan for the Office of Dietary Supplements 2004-2009. http://ods.od.nih.gov/pubs/SP10B.web.pdf.

2. [Internet] Washington, DC: Department of Health and Human Services, Office of the Surgeon General. Bone Health and Osteoporosis: A Report of the Surgeon General; 2004. http://surgeongeneral.gov/library/bonehealth/content.html.

3. Department of Health. Nutrition and bone health. London: The Stationery Office, 1998.

4. Ervin R, Wang C, Wright J, Kennedy-Stephenson J: Dietary intake of selected minerals for the United States population: 1999-2000. Adv Data. 2004; 341:1-5.

5. Tang BM, Eslick GD, Nowson C, et al. Use of calcium or calcium in combination with vitamin D supplementation to prevent fractures and bone loss in people aged 50 years and older: a meta-analysis. Lancet. 2007; 370:657-666.

6. Mayer AM: Historical changes in the mineral content of fruits and vegetables. Br Food J 2007; 99: 207-211.

7. Long C: Is chemical farming making our food less nutritious? Organic Gardening. 1999;:12.

8. Jack A: Nutrition under siege. One Peaceful World. Becket, MA: Kushi Institute newsletter. 1998: 1-8.

9. Briot K. Non-corticosteroid drug-induced metabolic bone disease. Presse Med. 2006; 35:1579-1583.

10. Unger L, Kayser M, Enderlein M, et al. Glucocorticoid therapy in collagen diseases. Z Rheumatol. 2005;64:162-9.

11. Waknine $Y$. Rosiglitazone linked to fracture risk in women. Medscape Med News 2007; February 21.

12. Tannirandorn P, Epstein S. Drug-induced bone loss. Osteoporos Int. 2000;11:637-659.

13. Richards JB, Joseph L, Schwartzman K, Kreiger N, Tenenhouse A, Goltzman D. The effect of cyclooxygenase-2 inhibitors on bone mineral density: results from the Canadian Multicentre Osteoporosis Study. Osteoporos Int. 2006;17(9):1410-9.

14. Bliziotes M. Update in serotonin and bone. J Clin EndoMetabolism 2010; 95: 4124-4132

15. Haney EM, Chan BK, Diem SJ, et al: Association of low bone mineral density with selective serotonin reuptake inhibitor use by older men. Arch Intern Med. 2007;167:1246-1251.

16. Yirmiya R, Goshen I, Bajayo A, Kreisel T, Feldman S, Tam J, Trembovler V, Csernus V, Shohami E, Bab I. Depression induces bone loss through stimulation of the sympathetic nervous system. Proc Natl Acad Sci U S A 2006;103:16876-16881. 17. Spangler L, Scholes D, Brunner RL, et al. Depressive symptoms, bone loss, and fractures in postmenopausal women. J Gen Intern Med. 2008;23:567-574.

18. Ott SM, Scholes D, LaCroiz AZ, et al. Effects of contraceptive use on bone biochemical markers in young women. J Clin Endocrinol Metab. 2001;86:179-185.

19. Register TC, Lenchik L, Applegate WB, Ettinger BHJr, Chao D, Espeland MA, Farmer D, et al. Effect of voluntary weight loss on bone mineral density in older overweight women. J Am Geriatr Soc. 2000;48:753-759.

20. Divine G, Rovner DR.Gossain VV, Rao DS, Carella MJ, et al. Bone mineral density (BMD) in obesity effect of weight loss. J Med. 1999;30:367-376.

21. Jensen LB, Kollerup G, Quaade F, Sorensen OH. Bone mineral changes in obese women during moderate weight loss with and without calcium supplementation. J Bone Miner Res. 2001; 16:141-147.

22. Larsen E, Mosekilde L, Foldspant A. Vitamin D and calcium supplementation prevents osteoporotic fractures in elderly community dwelling residents: a pragmatic population-based 3-year intervention study. J Bone Miner Res 2004; 19: 370-378.

23. Svendsen OL, Hendel HW, Gotfredsen A, et al. Are soft tissue composition of bone and non-bone pixel in spinal bone mineral measurements by DXA similar? Impact of weight loss. Clin Phisiol Funct Imaging. 2002;22:72-77. 
24. Ensrud KE, Ewing SK, Stone KL, et al. Intentional and unintentional weight loss increase bone loss and hip fracture risk in older women. J Am Geriatr Soc. 2003; 51:1740-1747.

25. Langlois JA, Mussolino ME, Visser M, et al. Weight loss from maximum body weight among middle-aged and older white women and the risk of hip fracture: the NHANES I epidemiologic follow-up study. Osteoporos Int. 2001;12:763-768.

26. Meyer HE, Tverdal A, Selmer R. Weight variability, weight change and the incidence of hip fracture: a prospective study of 39,000 middle-aged Norwegians. Osteoporos Int. 1998;8: 373-378.

27. Riedt CS, Cifuentes M, Stahl T, et al. Overweight postmenopausal women lose bone with moderate weight reduction and 1 g/day calcium intake. J Bone Miner Res. 2005;20:455-463.

28. Ensrud KE, Fullman RL, Barrett-Connor E, et al. Osteoporotic Fractures in Men Study Research Group. Voluntary weight reduction in older men increases hip bone loss: the osteoporotic fractures in men study. J Clin Endocrinol Metab. 2005;90:1998-2004.

29. Chao D, Espeland MA, Farmer D, et al. Effect of voluntary weight loss on bone mineral density in older overweight women. J Am Geriatr Soc. 2000;48:753-759.

30. Gossain VV, Rao DS, Carella MJ, et al. Bone mineral density (BMD) in obesity effect of weight loss. J Med. 1999;30:367-376.

31. Riedt CS, Brolin RE, Sherrell RM, et al. True fractional calcium absorption is decreased after Roux-en-Y gastric bypass surgery. Obesity (Silver Spring). 2006;4:1940-1948.

32. Johnson JM, Maher JW, Samuel I, et al. Effects of gastric bypass procedures on bone mineral density, calcium, parathyroid hormone, and vitamin D. J Gastrointest Surg. 2005;9:1106-1110.

33. Baxter-Jones ADG, Kontulainen SA, Faulkner RA, Bailey DA. A longitudinal study of the relationship of physical activity to bone mineral accrual from adolescence to young adulthood. Bone. 2008 Dec;43(6):1101-7

34. Lappe J, Cullen D, Haynatzki G, et al. Calcium and vitamin $\mathrm{D}_{3}$ supplementation decreases incidence of stress fractures in female navy recruits. J Bone Miner Res. 2008;23:741-749.

35. American College of Physicians position paper: Information on cost-effectiveness: an essential product of a national comparative effectiveness program. Ann Intern Med. 2008; 148:956-961.

36. Alexander GC, Stafford RS: Does comparative effectiveness have a comparative edge? JAMA. 2009; 301:2488-2490.

37. Kaats GR, Preuss HG, Leckie RB: Comparative effectiveness research (CER): opportunities and challenges for the nutritional industry. J Am Coll Nutr. 2009; 28:234-237.

38. Tunis SR, Stryer DG, Clancy CM: Practical clinical trials: increasing the value of clinical research for decision making in clinical and health policy. JAMA. 2003; 290:1624- 1632.

39. Avorn J: Debate about funding comparative-effectiveness research. N Engl J Med. 2009; 360: 1927- 1929.

40. Iglehart JK: Prioritizing comparative-effectiveness research--IOM recommendations. N Engl J Med 2009; 361: 325328.

41. Garber AM, Tunis SR: Does comparative-effectiveness research threaten personalized medicine? N Engl J Med 2009; 360: 19251927.

42. Jones G, Nguyen T, Sambrook P, et al. Progressive loss of bone in the femoral neck of elderly people: longitudinal findings from the Dubbo osteoporosis epidemiology study. BMJ 1994; 309:691-695.

43. Alborg $\mathrm{H}$, Johnell $\mathrm{O}$, Turner $\mathrm{C}$, et al. Bone loss and bone size after menopause. N Engl J Med 2003; 349:327-334.

44. National Osteoporosis Foundation. Clinician's Guide to Prevention and Treatment of Osteoporosis. Washington, DC: National Osteoporosis Foundation. 2005.

45. Emaus N, Berntsen GK, Joakimsen RM, et al. Longitudinal changes in forearm bone mineral density in women and men aged 25-44 years: the Tromsø Study: a population-based study. Am J Epidemiol 2005;162:633-643.

46. Bainbridge KE, Sowers $\mathrm{M}$, Lin X, et al. Risk factors for low bone mineral density and the 6-year rate of bone loss among premenopausal and perimenopausal women. Osteoporos Int 2004;15:439-446.

47. Chapurlat RD, Gamero P, Sornay-Rendu E, et al. Longitudinal study of bone loss in pre- and perimenopausal women: evidence for bone loss in perimenopausal women. Osteoporos Int 2000;11:493-498.

48. Guthrie JR, Ebeling PR, Hopper JL, et al. A prospective study of bone loss in menopausal Australian-born women. Osteoporos Int 1998;8(3):282-290.

49. Sowers M, Crutchfield M, Bandekar R, et al. Bone mineral density and its change in pre- and perimenopausal white women: the Michigan Bone Health Study. J Bone Miner Res 1998;13:1134-1140.

50. Burger $\mathrm{H}$, de Laet CE,van Daele PL, et al. Risk factors for increased bone loss in an elderly population: the Rotterdam Study. Am J Epidemiol 1998;147:871-879.

51. Hannan MT, Felson DT, Dawson-Hughes B, et al. Risk factors for longitudinal bone loss in elderly men and women: the Framingham Osteoporosis Study. J Bone Miner Res. 2000;15:710-720.

52. Jones G, Nguyen T, Sambrook P, et al. Progressive loss of bone in the femoral neck of elderly people: longitudinal findings from the Dubbo osteoporosis epidemiology study. BMJ 1994; 309:691-695.

53. Alborg $\mathrm{H}$, Johnell $\mathrm{O}$, Turner $\mathrm{C}$, et al. Bone loss and bone size after menopause. N Engl J Med 2003; 349:327-334.

54. Wilsgaard T, Emaus N, Ahmed LA, Grimnes G, Joakimsen RM, Omsland TK, Bernstsen GR. Lifestyle impact on lifetime bone loss in women and men:The Tromso Study. Am J Epidemiol 2009; 169: 877-886.

55. Jackson RD, LaCroix AZ, Gass M, et al. Women's Health Initiative Investigators. Calcium plus vitamin $\mathrm{D}_{3}$ supplementation on bone density and the risk of fractures. N Engl J Med. 2006; 354:669-683.

56. Dawson-Hughes B, Harris SS, Krall EA, et al. Effect of calcium and vitamin D supplementation on bone density in men and women 65 years of age or older. N Engl J Med. 1997; 337:670-676.

57. Chapuy MC, Pamphile R, Paris E, et al. Combined calcium and vitamin D3 supplementation in elderly women: confirmation of reversal of secondary hyperparathyroidism and hip fracture risk: the Decalyos II study. Osteoporos Int. 2002; 13:257-264.

58. Zhu K, Bruce D, Austin N, et al. A randomized controlled trial of the effects of calcium with or without vitamin $\mathrm{D}$ on bone structure and bone related chemistry in elderly women with vitamin D insufficiency. J Bone Miner Res. 2008; 23:1343-1348.

59. Chel V, Wijnhoven HA, Smit JH, et al. Efficacy of different doses and time intervals of oral vitamin $\mathrm{D}$ supplementation with or without calcium in elderly nursing home residents. Osteoporos Int. 2008; 19:663-671.

60. Adluri RS, Zhan L, Bagchi M, et al: Comparative effects of a novel plant-based calcium supplement with two common calcium salts on proliferation and mineralization in human osteoblast cells. Mol Cell Biochem. 2010; 340:73-80.

61. Marone PA, Yasmin T, Gupta RC, et al: Safety and toxicological evaluation of AlgaeCal (AC), a novel plant-based calcium supplement. Toxicol Mech Methods. 2010; 20:334-344.

62. Kaats GR: The Clicker, The Glycemic Index and the Glycemic Load, Estimating and Balancing Calories. In: Restructuring Body Composition: How the Kind, Not the Amount, of Weight Loss Defines a Pathway to Optimal Health. Dallas: Taylor Publishing; 2008:223-294. 
63. Schneider PL, Crouter SE, Bassett DR: Pedometer measures of free-living physical activity: comparison of 13 models. Med Sci Sports Exerc. 2004; 36:331-335.

64. Kaats GR: The effect of glyconutritional plant polysaccharides on quality of life. In: Restructuring Body Composition: How the Kind, Not the Amount, of Weight Loss Defines a Pathway to Optimal Health. Dallas: Taylor Publishing; 2008:212-222.

65. Meunier PJ, Slosman DO, Delmas PD, et al: Strontium ranelate: dose-dependent effects in established postmenopausal vertebral osteoporosis--a 2-year randomized placebo controlled trial. J Clin Endocrinol Metab. 2002; 87:2060-2066.

66. Meunier PJ, Roux C, Seeman E, et al: The effects of strontium ranelate on the risk of vertebral fracture in women with postmenopausal osteoporosis. N Engl J Med. 2004; 350:459-468.

67. Reginster JY, Seeman E, De Vernejoul MC, et al: Strontium ranelate reduces the risk of nonvertebral fractures in postmenopausal women with osteoporosis: Treatment of Peripheral Osteoporosis (TROPOS) study. J Clin Endocrinol Metab. 2005; 90:2816-2822.

68. Nieves JW: Osteoporosis: the role of micronutrients. Am J Clin Nutr.2005; 81:S1232-S1239.

69. Brown SE: Maximizing nutrient intake. In: Better Bones, Better Body: Beyond Estrogen and Calcium. Los Angeles: Keats Publishing; 2000:246.

70. Holick MF: Vitamin D deficiency. N Engl J Med. 2007; 357:266-281.

71. Tucker KL, Chen H, Hannan MT, et al: Bone mineral density and dietary patterns in older adults: the Framingham Osteoporosis Study. Am J Clin Nutr. 2002; 76:245-252.

72. Sahni S, Hannan MT, Gagnon D, et al: High vitamin C intake is associated with lower 4-year bone loss in elderly men. J Nutr. 2008; 138:1931-1938.

73. Lanham-New SA: Fruit and vegetables: the unexpected natural answer to the question of osteoporosis prevention? Am J Clin Nutr. 2006; 83:1254-1255.

74. New S, Robins SP, Campbell MK, et al: Dietary influences on bone mass and bone metabolism: further evidence of a positive link between fruit and vegetable consumption and bone health? Am J Clin Nutr. 2000; 71:142-151.

75. Macdonald HM, New SA, Golden MH, et al: Nutritional associations with bone loss during the menopausal transition: evidence of a beneficial effect of calcium, alcohol, and fruit and vegetable nutrients and of a detrimental effect of fatty acids. Am J Clin Nutr. 2004; 79:155-165.

76. New SA: Intake of fruit and vegetables: implications for bone health. Proc Nutr Soc. 2003; 62:889-899.

77. Prynne CJ, Mishra GD, O'Connell MA, et al: Fruit and vegetable intakes and bone mineral status: a cross sectional study in 5 age and sex cohorts. Am J Clin Nutr. 2006; 83:1420-1428.

78. Tucker KL, Hannan MT, Chen H, et al: Potassium, magnesium, and fruit and vegetable intakes are associated with greater bone mineral density in elderly men and women. Am J Clin Nutr. 1999; 69:727-736.

79. Tucker KL, Chen H, Hannan MT, et al: Bone mineral density and dietary patterns in older adults: the Framingham Osteoporosis Study. Am J Clin Nutr. 2002; 76:245-252.

80. McGartland CP, Robson PJ, Murray LJ, et al: Fruit and vegetable consumption and bone mineral density: the Northern Ireland Young Hearts Project. Am J Clin Nutr. 2004; 80:1019-1023.

81. Jones G, Riley MD, Whiting S: Association between urinary potassium, urinary sodium, current diet, and bone density in prepubertal children. Am J Clin Nutr. 2001; 73:839-844. 